\title{
Evaluation of antimicrobial activity and phytochemical analysis of sicilian lemon peel (Citrus lemon Burm).
}

\author{
*Racowski I, Piotto J, Procópio V \\ Termomecanica Technology College-FTT, Estrada dos Alvarengas, São Bernardo do Campo, Brazil
}

Accepted on November 2, 2017

\section{Editorial}

Lemon is a fruit easily found and produced throughout the year [1]. This fruit is widely used in the food, cosmetics and pharmaceutical industries mainly due to the essential oil present in its peel $[2,3]$. The main components of this fruit are limonene, p-cymene, terpenenol and citral, the first being the main constituent of its essential oil [4,5]. In this context and regarding the constant and unrestrained use of chemical preservatives, especially antibiotics, as well as due to the fact that many microorganisms develop resistance in relation to these antibiotics, substances that are naturally present in foods that can act on microorganisms, retarding their development and increasing the useful life of foods where they are present have been studied, as is the case of this work, whose aim was to study the possibility of extracts (alcoholic and aqueous cold and hot) of the Sicilian lemon peel at proportions of $0,5,10$, $15,20,25$ and $100 \%$ to have antimicrobial activity against bacteria Escherichia coli and Staphylococcus aureus and yeast Saccharomyces cerevisae. The extracts were carried out using the protocol described by Racowski, et al. [6] and the microbial inhibition assays commonly use the agar diffusion method and the Miller Hinton $(\mathrm{MH})$ culture medium for bacteria and the Potato Dextrose Agar (PDA) culture medium for yeast [7,8]. The composition of these extracts was also checked by rapid tests: tannin test, saponin test, flavonoid test, terpenoid test and carbohydrate test [9]. The diameter of zone of inhibition around each well was measured with the aid of a digital caliper, each inhibition zone being measured in triplicate (in three different ways to reduce error due to irregular growth) and submitted to Kruskal Walis analysis of variance and compared by the Mann Whitney test, both with 5\% significance using the Action Stat software (Version 3.1, Estatcamp, Brazil). With the result, it was possible to verify that the extracts of the Sicilian lemon peel presented tannins, flavonoids and terpenoids in their composition and inhibitory activity against the growth of microorganisms in a differentiated way. Regarding the bacteria under study, all extracts showed inhibition halos, and the best $E$. coli inhibitor was the alcoholic extract $(100 \%-21.1 \mathrm{~mm})$. In addition, it is worth mentioning that in the case of alcoholic extracts and cold aqueous extract at concentration of $10 \%$, there was growth inhibition of this bacterium in Petri dishes, forming halos in the order of $15.0 \mathrm{~mm}$. In the hot aqueous extract, this occurred only from the concentration of $15 \%$. The same was verified for S. aureus, however, with the formation of smaller halos (10\%-1.2 mm) when compared to E. coli. In the case of hot aqueous extract, the inhibition halo was $4.6 \mathrm{~mm}$ for the first concentration that showed inhibition (15\%). cerevisae was the most difficult to inhibit since the cold aqueous extract showed no inhibition at any of the concentrations, whereas the hot aqueous extract showed inhibition only when used at concentration of $100 \%$, but the inhibition halo was small $(7.7 \mathrm{~mm})$. The alcoholic extract showed inhibition of yeast growth at concentration of $15 \%$ (15\%-10.3 mm, 20\%-11.4 mm, 25\%-11.4 mm and 100\%-12.0 $\mathrm{mm})$. Thus, the results obtained showed that the alcoholic and aqueous extracts of the Sicilian lemon peel can serve as an alternative to inhibit the growth of bacteria E. coli and S. aureus and yeast S. cerevisiae.

\section{References}

1. Trucom C. The Power of Lemon Cure. Brazil. 2004.

2. Kobori CN, Jorge N. Characterization of the oils extracted from the orange and passion fruit seeds as a use of industrial waste. South Regional Meeting of Food Science and Technology, Brazil. 2003.

3. de Rodriguez GO. Composition of Ven Composition of Venezuelan lemon essential oil Citrus limon (L.) Burm. Ver Fac Agron.1998;15:343-9.

4. Kunicka-styczyn A, Sikora M, Kalemba D. Antimicrobial activity of lavender, tea tree and lemon oils in cosmetic preservative systems. J Appl Microbiol. 2009;107:1903-11.

5. Rozza AL, Moraes TM, Kushima H, et al. Gastroprotective mechanisms of Citrus lemon (Rutaceae) essential oil and its majority compounds limonene and $\beta$-pinene: Involvement of heat-shock protein-70, vasoactive intestinal peptide, glutathione, sulfhydryl compounds, nitric oxide and prostaglandin E2. Chem Biol Interact. 2011;189:82-9.

6. Racowski I, Piotto J, Procópio V, et al. Evaluation of Antimicrobial Activity and Phytochemical Analysis of Thaiti Lemon Peels (Citrus latifolia Tanaka). J Microbiol Res. 2017;7:39-44.

7. Olivares MM, Roperol P, Marti R. et al. Antimicrobial potential of four Lactobacillus strains isolated from breast milk, Spain. J Appl Microbiol. 2006;101:72-9.

8. Johnson T, Case C. 4th ed, Laboratory Experiments in Microbiology. 1995.

9. Pathak P, Saraswath YA, Savai J. In vitro antimicrobial activity and phytochemical analysis of the leaves of Annona muricata. Int J Pharma Res Dev. 2010;2:1-6. 
Citation: Racowski I, Piotto J, Procópio V. Evaluation of antimicrobial activity and phytochemical analysis of sicilian lemon peel (Citrus lemon Burm). Microbiol Curr Res 2017;1(1):3-4.

\section{*Correspondence to}

Ilana Racowski

Termomecanica Technology College-FTT

Estrada dos Alvarengas, São Bernardo do Campo

Brazil

E-mail: ilmb@ig.com.br 